SANDIA REPORT

SAND97-2630 • UC-704

Unlimited Release

Printed November 1997
RECFIVED

DEC 151997

OSTI

\title{
Nonlinear Viscoelastic Response of Carbon Black-Filled Butyl Rubber and Implications for O-Ring Aging
}

Douglas Adolf

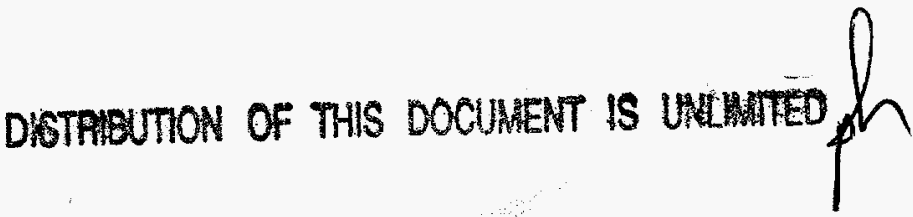

Prepared by

Sandia National Laboratories

Albuquerque, New Mexico 87185 and Livermore, California 94550

Sandia is a multiprogram laboratory operated by Sandia Corporation, a Lockheed Martin Company, for the United States Department of Energy under Contract DE-AC04-94AL85000.

Approved for public release; further dissemination unlimited.

\section{(iv) Sandia National Laboratories}

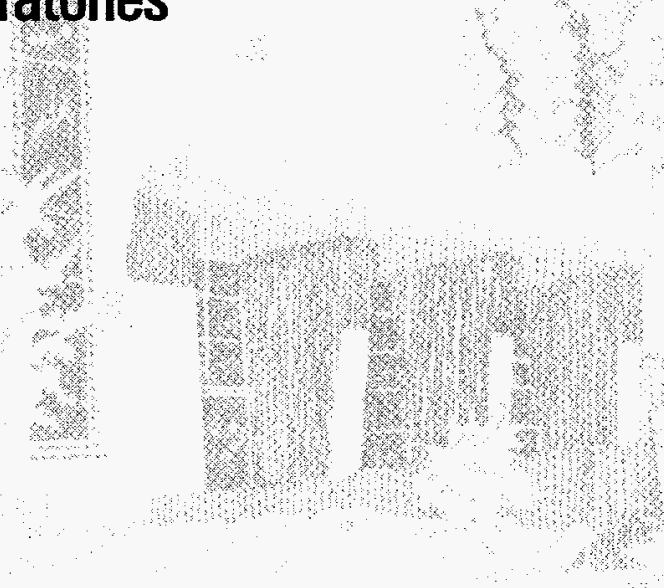


Issued by Sandia National Laboratories, operated for the United States Department of Energy by Sandia Corporation.

NOTICE: This report was prepared as an account of work sponsored by an agency of the United Sitates Government. Neither the United States Government nor any agency thereof, nor any of their employees, nor any of their contractors, subcontractors, or their employees, makes any warranty, express or implied, or assumes any legal liability or responsibility for the accuracy, completeness, or usefulness of any information, apparatus, product, or process disclosed, or represents that its use would not infringe privately owned rights. Reference herein to any specific commercial product, process, or service by trade name, trademark, manufacturer, or otherwise, does not necessarily constitute or imply its endorsement, recommendation, or favoring by the United States Government, any agency thereof, or any of their contractors or subcontractors. The views and opinions expressed herein do not necessarily state or reflect those of the United States Government, any agency thereof, or any of their contractors.

Printed in the United States of America. This report has been reproduced directly from the best available copy.

Available to DOE and DOE contractors from

Office of Scientific and Technical Information

P.O. Box 62

Oak Ridge, TN 37831

Prices available from (615) 576-8401, FTS 626-8401

Available to the public from

National Technical Information Service

U.S. Department of Commerce

5285 Port Royal Rd

Springfield, VA 22161

NTIS price codes

Printed copy: A03

Microfiche copy: A01 


\section{DISCLAMERR}

Portions of this docarnent may be illegible in electronic irogge prodietc. Imsges are produced from the best arailable original docementert 
SAND 97-2630

Unlimited Release

Printed November 1997

\title{
Nonlinear Viscoelastic Response of Carbon Black-Filled Butyl Rubber and Implications for O-Ring Aging
}

\author{
Douglas Adolf \\ Theoretical and Computational Materials Modelling Department \\ Sandia National Laboratories \\ P.O. Box 5800 \\ Albuquerque, NM 87185-0333
}

\begin{abstract}
Butyl rubber, unfortunately, has pronounced nonlinear viscoelastic behavior, which may be modelled by a separable KBKZ formalism. While these effects seem to have minimal impact on accelerated sealing force measurements, they do severely impact compression set tests. Therefore, a new test is suggested for evaluating field-return o-rings which is free from such confounding effects.
\end{abstract}




\section{Introduction}

Butyl rubber o-rings have wonderful permeation characteristics but historically poor aging performance. Ken Gillen (SNLNM) has shown that oxygen diffusion limitations may severely influence predictions of o-ring lifetime from high temperature accelerated aging tests. ${ }^{1}$ In this report, we wish to characterize the nonlinear viscoelasticity (NLVE) of carbon blackfilled butyl rubbers and assess its importance on o-ring lifetime predictions and on evaluation of o-rings returning from the stockpile.

A Parker sheet stock butyl rubber was used in all tests. The nominal sheet thickness was $1.15 \mathrm{~mm}$. Carbon black loading levels were approximately 18 vol.\%. The samples were post-cured for 8 hours at $100{ }^{\circ} \mathrm{C}$ prior to testing due to concerns of incomplete cure of the sheet stock. That these concerns were justified will be discussed later. All rheological tests were performed on a Rheometrics RMS-800 with annular parallel plates. With this geometry, the strain was relatively homogeneous throughout the sample. The rubber "doughnuts" were glued to the plates with a cyanoacrylate glue, which we found useful on previous investigations of carbon black-filled rubbers.2,3 The compressive stress relaxation data used in this report was collected previously by Ken Gillen and Mark Wilson (Allied-Signal, Kansas City) under conditions which minimize oxygen diffusion limitations. From these compressive tests, we calculated the shear moduli [for comparison with the true shear data] using the standard relation

$$
\sigma_{\text {compr }}=\frac{F_{\text {compr }}}{A_{o}}=G\left(\lambda-\frac{1}{\lambda^{2}}\right)
$$

where $A_{0}$ is the undeformed area and $\lambda$ is the extension ratio, $\Delta L / L_{0}$. 


\section{Linear Viscoelasticity of Unaged Butyl}

We first investigated the linear viscoelastic stress relaxation moduli of the filled butyl rubber at strains of $0.5 \%$ at temperatures of 30,70 , and $120^{\circ} \mathrm{C}$. Since the tests only lasted five minutes, we would expect that no chemical degradation occurred in even the $120^{\circ} \mathrm{C}$ tests, and repeat tests confirmed our expectations. The shear stress relaxation moduli, G, for these conditions are shown in Fig. 1.

Following standard procedures, we attempted to construct timetemperature superposition master curves ${ }^{4}$ solely by horizontally shifts. The "WLF" equation

$$
\log a(T)=\frac{-C_{1}\left(T-T_{o}\right)}{C_{2}+T-T_{o}}
$$

describes how these horizontal shifts, a(T), vary with test temperature relative to a reference temperature of $\mathrm{T}_{0}$. One might reasonably assume that the unfilled butyl rubber shift factors, $C_{1}=9.0$ and $C_{2}=200$ at $\mathrm{T}_{\mathrm{o}}=22^{\circ} \mathrm{C}, 4$ would equally well describe the filled system, and, in fact, this procedure worked well for the carbon black-filled natural rubbers studied previously. 2 However, in Fig. 2, we see that this assumption fails miserably for butyl rubber. We now have two choices: (1) simply find the "best" horizontal shift factors [also shown in Fig. 2] or (2) apply vertical shifts as well as horizontal shifts.

This debate about vertical vs. horizontal shifting has raged in the rubber community for decades without resolution. It has been fueled by the confusing behavior of differing samples; some filled rubbers seem to obey the unfilled WLF shift factors while others do not, just as we observed for natural and butyl. It has also been plagued by the functional form of the slowly decaying stress relaxation modulus. In order to distinguish between horizontal and vertical shifts, we need significant curvature in G. In fact, it can be proven that no deconvolution is possible for purely power-law 
Fig. 1: Linear Viscoelastic Response

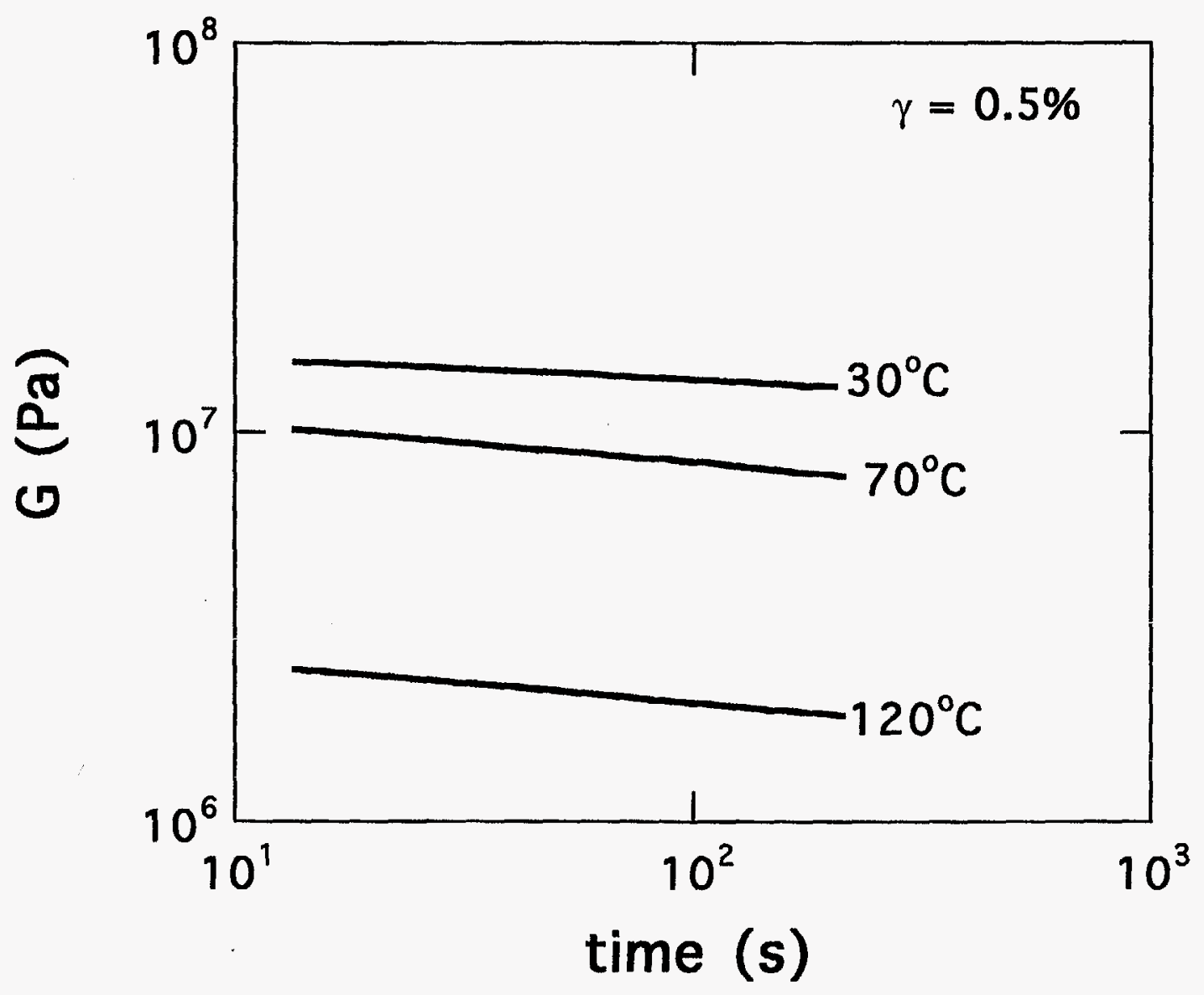


Fig. 2: Attempts to Produce Time-Temperature Master Curves

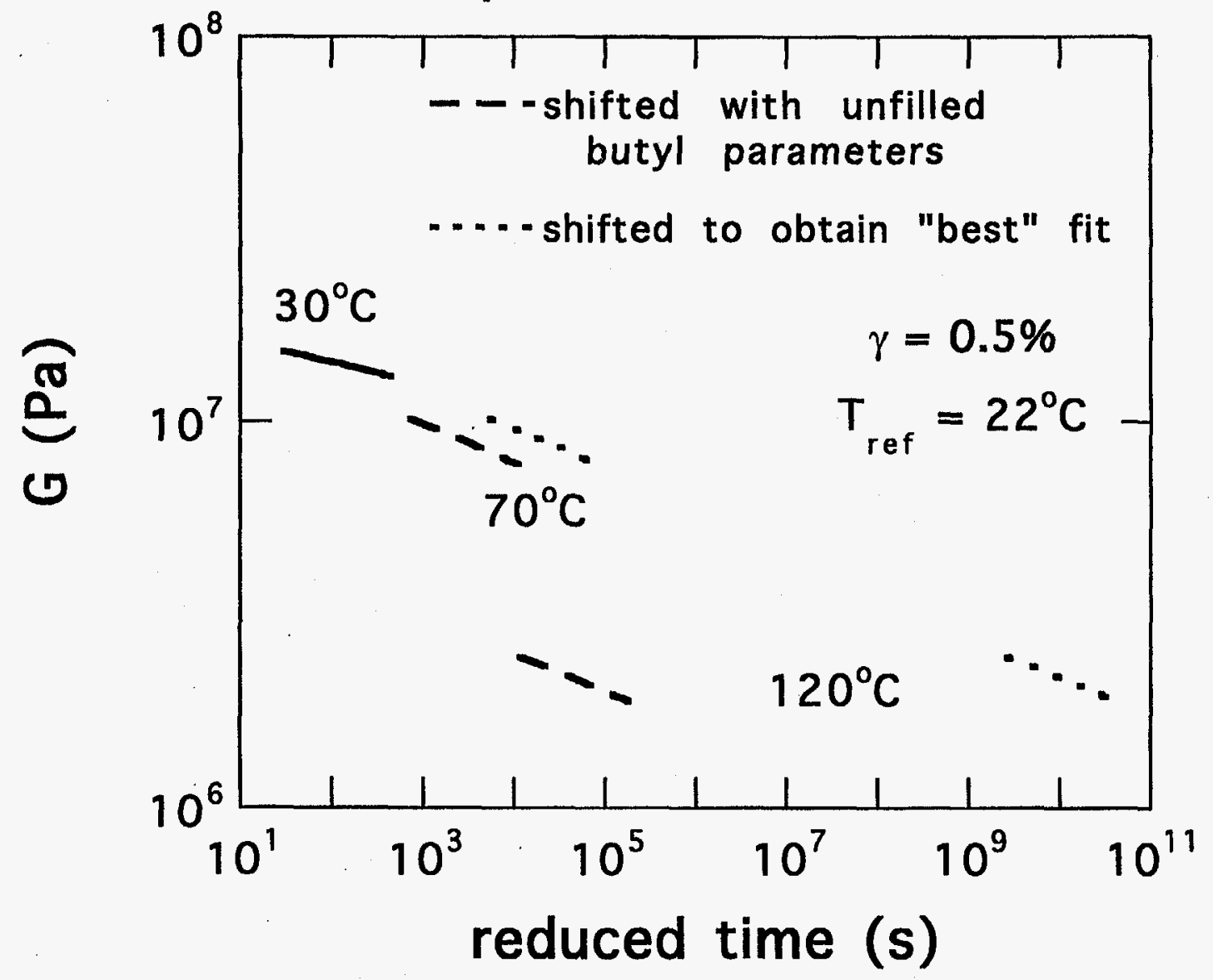


decay, which the data seem to approach. The unfortunate fact is that no experiments have yet been devised that cleanly resolve this controversy and we can offer no new insight. We will examine more data and investigate practical implications later in this manuscript.

\section{Nonlinear Viscoelasticity of Unaged Butyl}

We will now forge on and investigate the nonlinear viscoelastic response of the stress relaxation modulus to larger strains. Figs. 3-5 show this response to strains from 0.5 to $25 \%$ at temperatures from 30,70 , to $120^{\circ} \mathrm{C}$. We see dramatic strain softening; at $30^{\circ} \mathrm{C}, \mathrm{G}$ drops by almost an order of magnitude from applied strains of $0.5 \%$ to $25 \%$. However, in Fig. 6 , we clearly see that the strain softening itself softens as temperature increases. At $120^{\circ} \mathrm{C}, \mathrm{G}$ only drops by a factor of two from 0.5 to $20 \%$ strain. Returning to Fig. 5 , we see that the slope of the curves at $120^{\circ} \mathrm{C}$ decreases as the strain increases. This may be a sign that we are "bumping" into the equilibrium modulus, $\mathrm{G}_{\infty}$; that is, the lore of carbon black-filled rubbers suggests that softening only exists in the decaying portion of the stress relaxation modulus and not in the truly elastic portion, $\mathrm{G}_{\infty}$. Therefore, at high temperatures where the relaxations are greatly accelerated and at high strains where the response is greatly softened, we may have decayed and softened to the point at which the decaying portion of $G$ becomes comparable to the magnitude of $G_{\infty}$. In other words,

$$
G(t)=G_{d}(t)+G_{\infty}
$$

and $G_{\infty} \approx G_{d}(t)$ at high temperatures and high strains. From Fig. 5, we estimate that $G_{\infty}$ is roughly $1 \times 10^{6} \mathrm{~Pa}$. In Fig. 7, we show only the decaying portion of $G$ [i.e. $\left.G_{d}=G-G_{\infty}=G-1 \times 10^{6}\right]$. We now see that the curves at different strains now have roughly the same slope and the apparent strain softening is greater. 


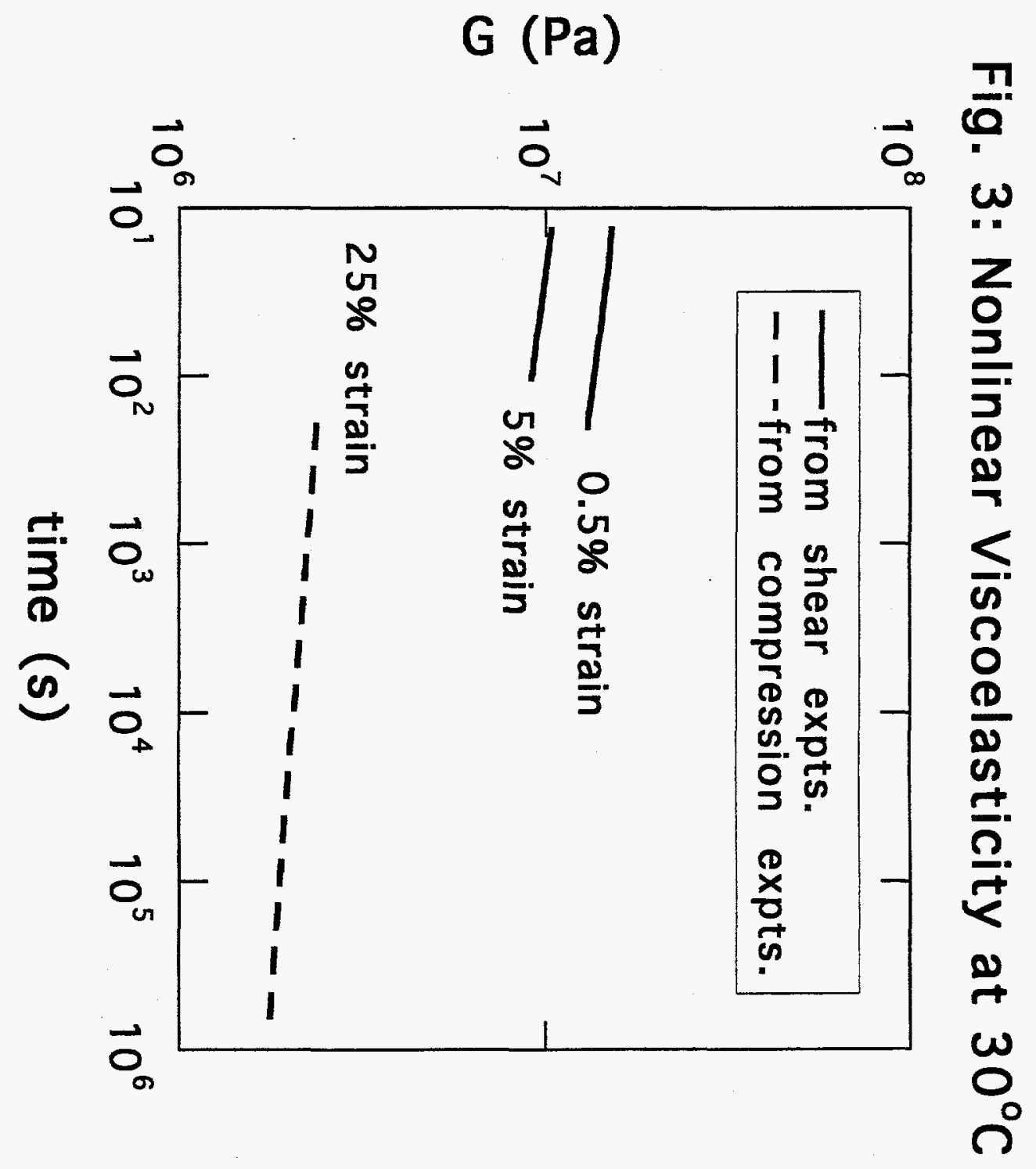




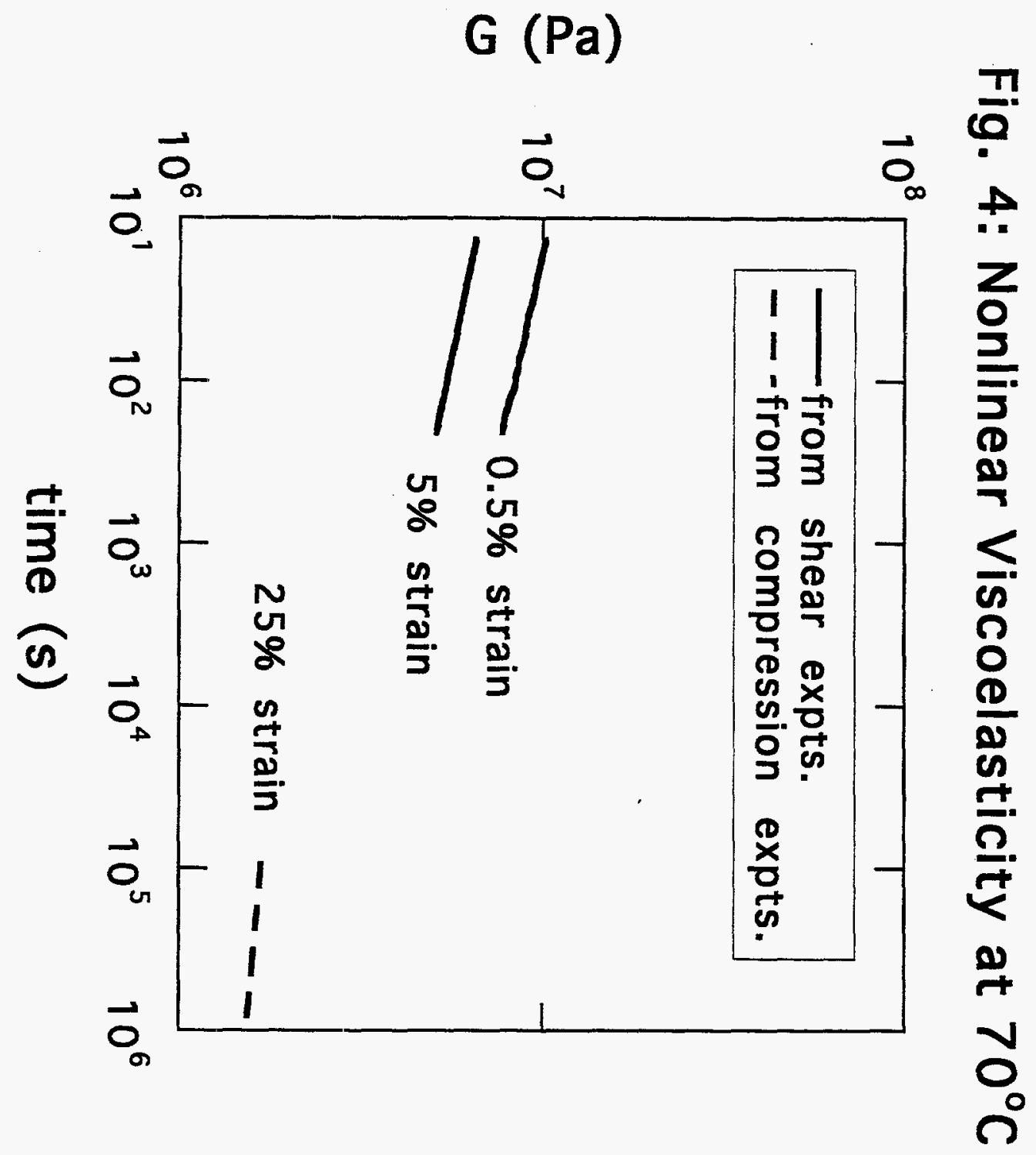




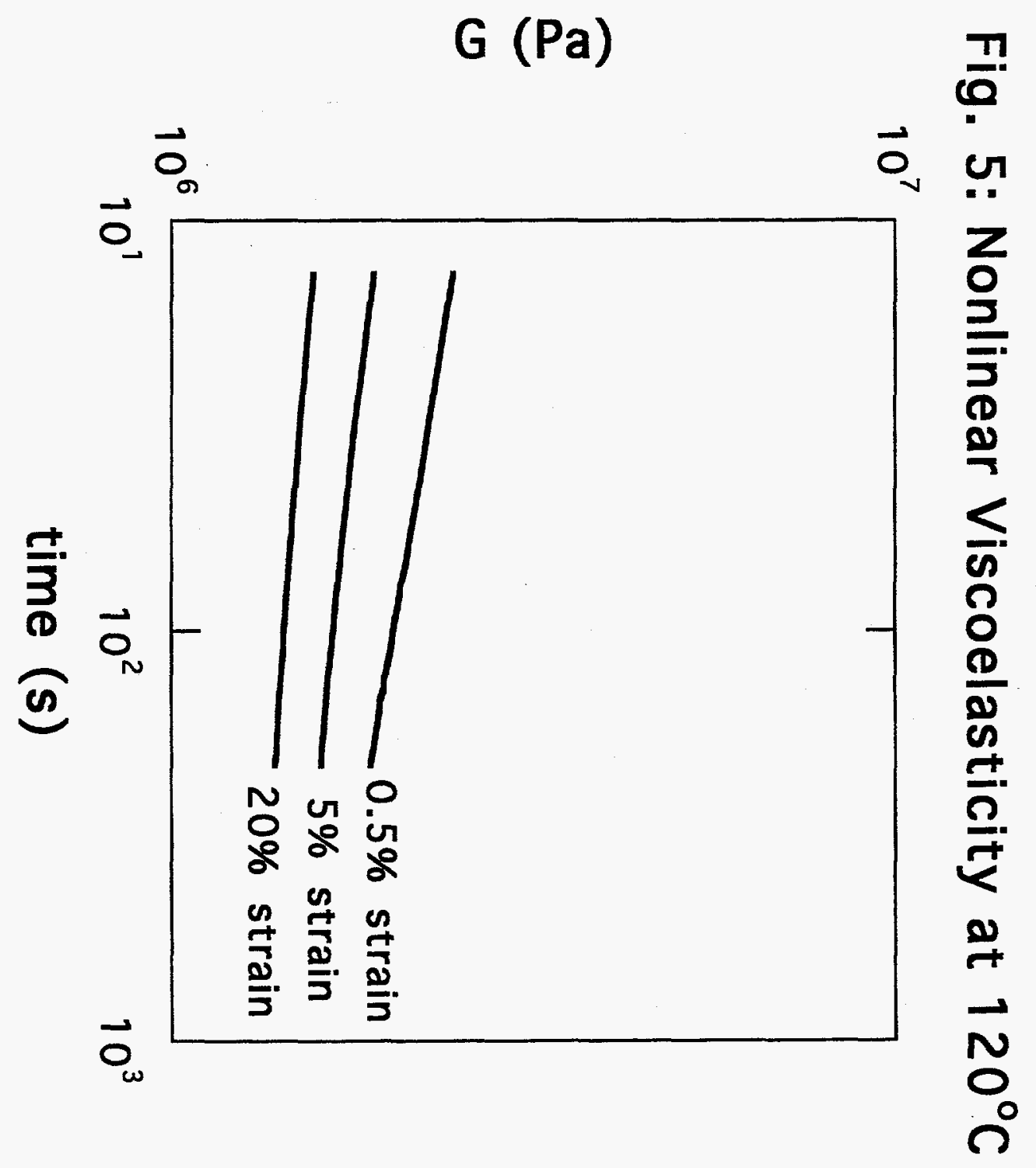


Fig. 6: Comparison of NLVE at Different Temperatures

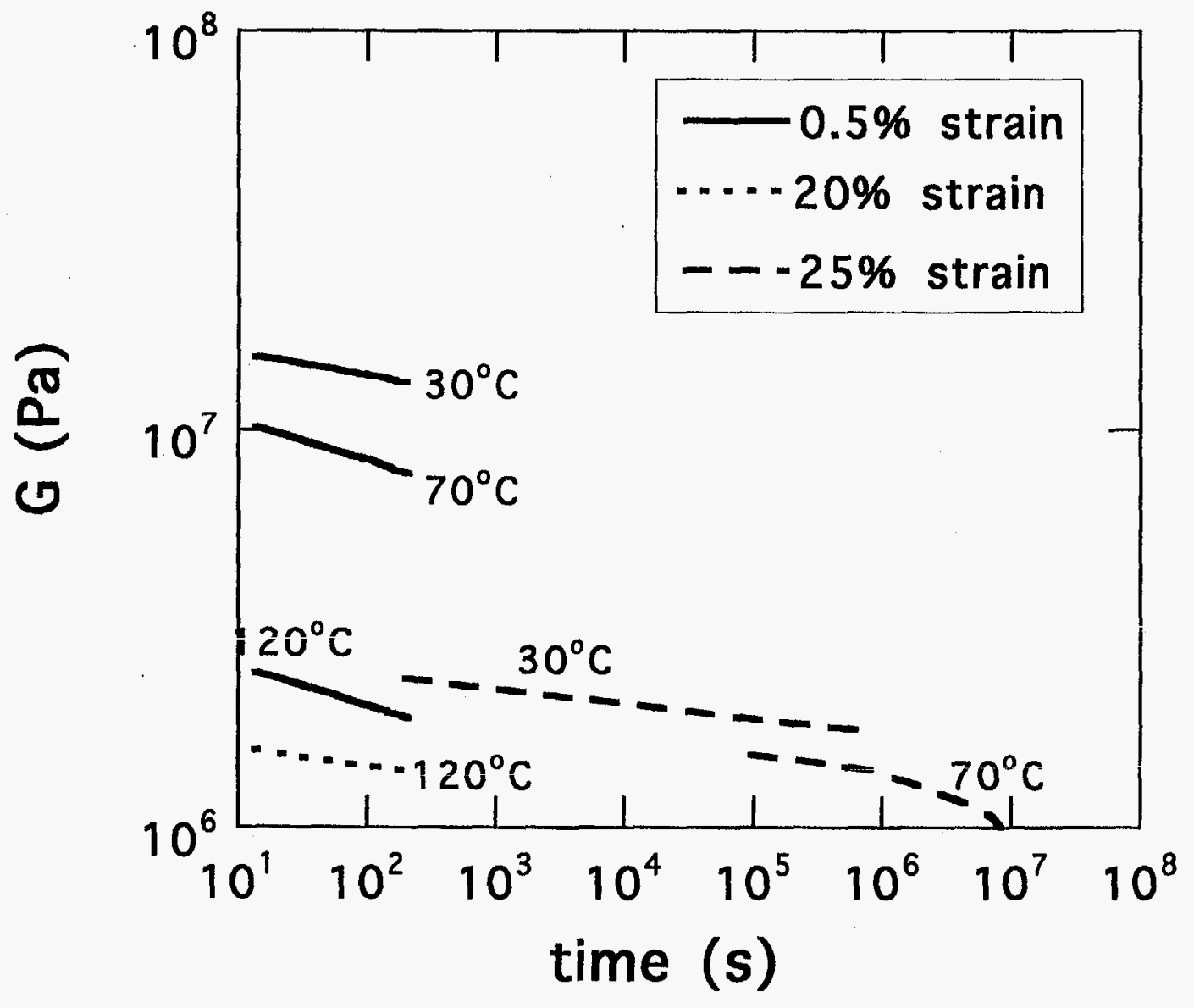




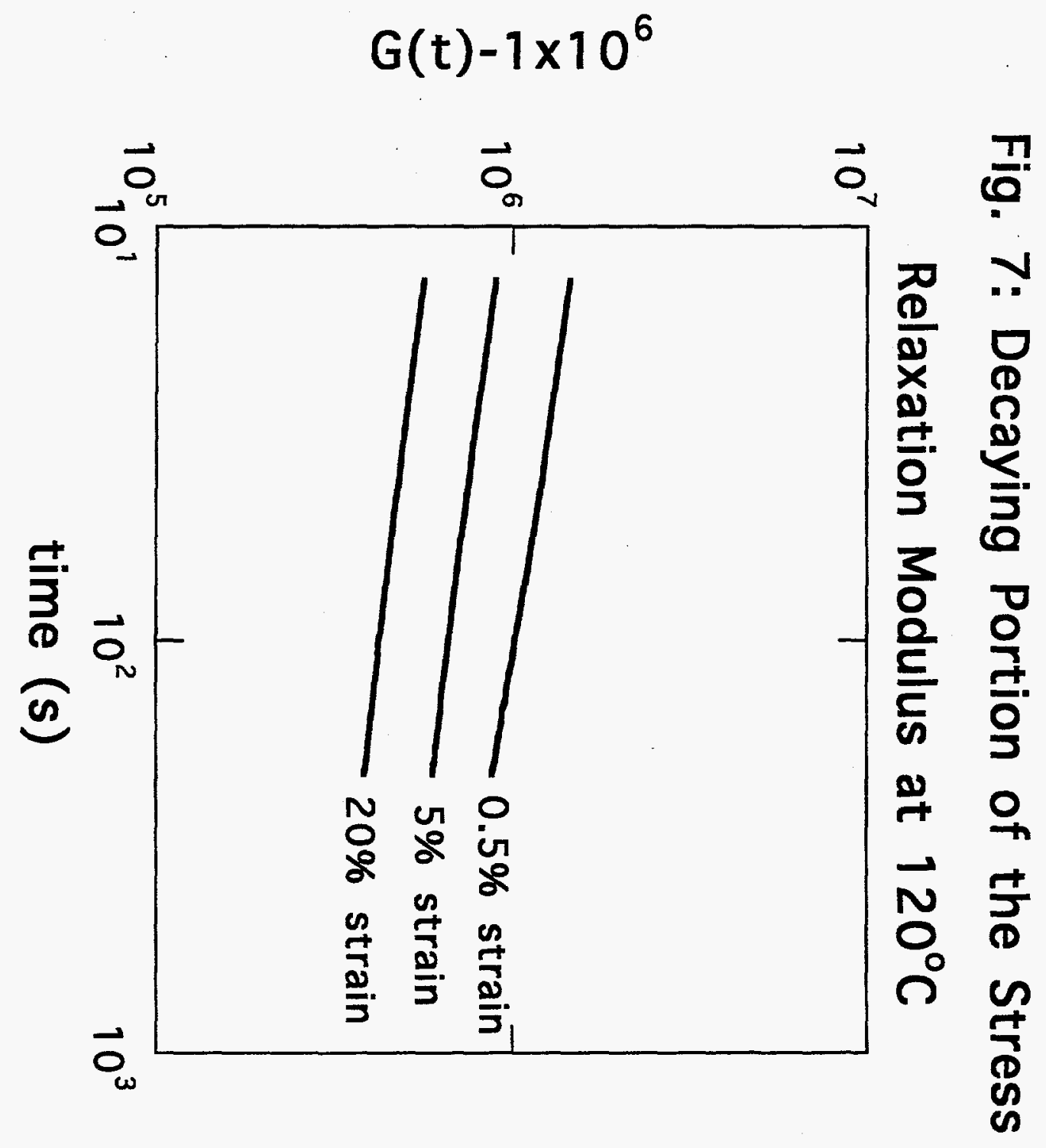


We previously ${ }^{2}$ described the strain softening of carbon black-filled rubber by a separable $\mathrm{KBKZ}$ formalism. ${ }^{5}$ In this formalism, the time dependence at each strain is identical and only the magnitude of $G_{d}$ is softened by a "damping function", h. For shear strains,

$$
\begin{gathered}
\sigma(t)=\int_{-\infty}^{t} d s m(t-s) h[\gamma(t)-\gamma(s)][\gamma(t)-\gamma(s)]+G_{\infty} \gamma(t) \\
\text { where } m(t)=-\frac{d G}{d t}(t)
\end{gathered}
$$

For more complicated strain histories, a proper tensorial version is available and for nonisothermal operation, one must employ the reduced time, $\xi(t)$, instead of the actual time to account for the acceleration of relaxation times with increasing temperature. The reduced time is defined as

$$
\xi(t)=\int_{0}^{t} \frac{d s}{a(T(s))}
$$

where $a$ is the shift factor of Eq. 2.

From Figs. 3, 4, and 7, it appears that $\mathrm{KBKZ}$ may apply to carbon black-filled butyl rubber as well, in that the relaxation spectra are relatively unchanged by strain [a requirement of separability]. In Fig. 8, we plot the vertical [strain softening] shifts from Figs. 3, 4, and 7 and obtain a reasonably universal curve [the curve in Fig. 8 is only to guide the eye]. However, a big uncertainty in applying the $\mathrm{KBKZ}$ formalism to butyl, again, lies in the ambiguous definition of the WLF shift factors required for Eq. 5. 


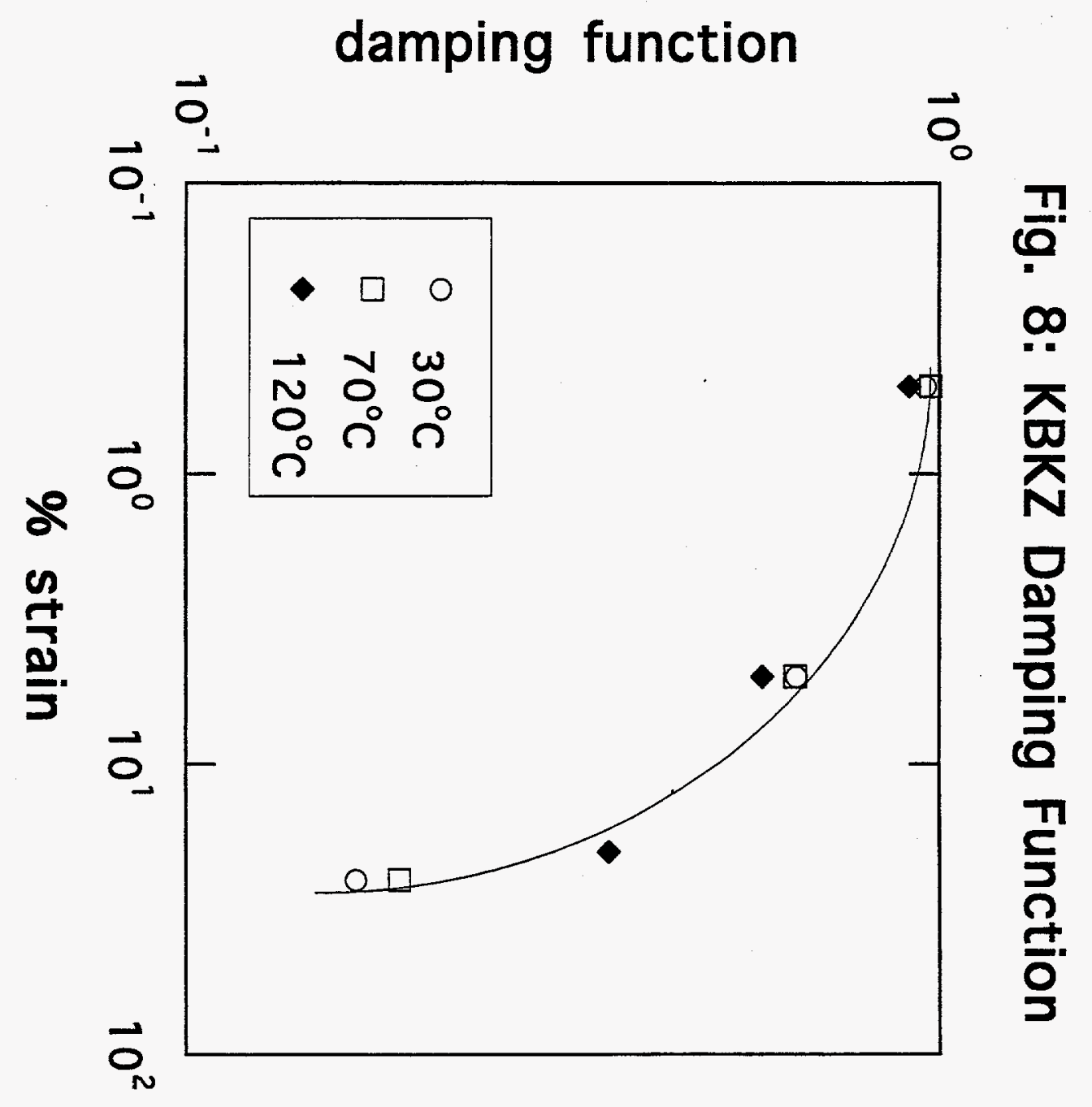




\section{Nonlinear Viscoelasticity of Aged Butyl}

\section{A. Aging with no Applied Strain}

We now turn toward the aging of butyl. Annular samples $1 \mathrm{~mm}$ thick by $2 \mathrm{~mm}$ wide [i.e. $12 \mathrm{~mm} \mathrm{O.D}$ and $10 \mathrm{~mm}$ I.D.] were aged at $110^{\circ} \mathrm{C}$ for up to one month. In this geometry, diffusion limited oxidation effects should be minimal. In Fig. 9, we show the stress relaxation modulus at $120^{\circ} \mathrm{C}$ and $20 \%$ applied strain as a function of aging time. No dramatic effect can be observed except for the as-received sample. Ignoring day 0 for now, we see that although there is some variation in the remainder of the data, there is no trend. This suggests sample-to-sample variations, which is verified by repeat tests.

The noticeable difference between day 0 and day 1 is related to our concerns over the undercuring of the as-received sheet stock. The modulus increased by roughly a factor of two implying that the sheet stock was, indeed, not fully cured. Our standard procedure of an 8 hour, $100^{\circ} \mathrm{C}$ cure on the as-received sheet stock eliminates this concern.

The lack of any apparent change in modulus with aging time does not imply that chemistry is not occurring. In the following section, we show that much degradation does occur. However, this particular test, in which we age unstrained in an oven and transfer the aged sample to the rheometer for testing, is sensitive to the total crosslink density. Our observed modulus invariance is then a reflection of the fact that a roughly equal number of crosslinks are formed as are broken. Note that, by testing at a high temperature and high strain, we are purposefully probing the equilibrium modulus, $\mathrm{G}_{0}$, which is proportional to the crosslink density [from the discussion surrounding Figs. 5 and 7]. 


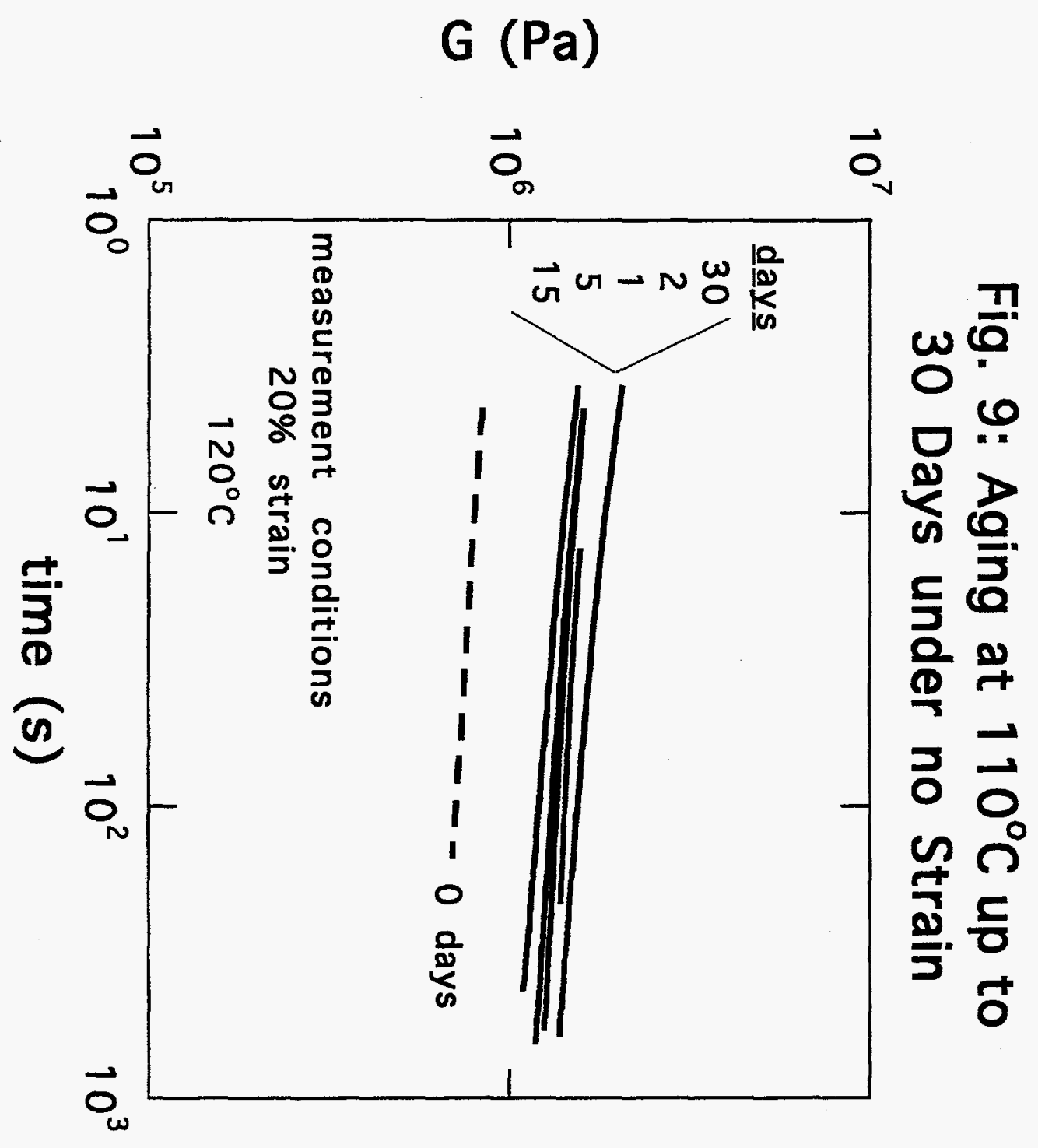




\section{B. Aging Under Compressive Strain}

By monitoring the change in stress of a sample under constant compression as a function of time at elevated temperatures, we are now probing only the crosslink scission. Crosslinks that are broken reduce the stress, but new crosslinks are unstrained when formed in the macroscopically compressed state and, therefore, do not contribute to the measured stress. In Fig. 10, we see data previously acquired by Ken Gillen and Mark Wilson which clearly shows the degradation chemistry under $25 \%$ compressive strain. Ken Gillen previously analyzed this data and obtained a bond breakage kinetic activation energy of roughly $19 \mathrm{kcal} / \mathrm{mole}$ by considering chemistry alone without viscoelastic complications.

That ignoring viscoelasticity is valid can probably best be seen back on Fig. 6. Compressive stress relaxation measurements typically employ strains of $25 \%$ and temperatures from 70 to $110^{\circ} \mathrm{C}$. From Fig. 6, we concluded that experiments with high strains and high temperatures are sensitive mainly to the equilibrium modulus, which itself is a direct indicator of crosslink density. Therefore, chemistry alone dominates the typical compressive stress relaxation experiments. However, if one employs much lower strains, such a conclusion may no longer be valid.

Only one confounding factor remains and is displayed in Fig. 11. Here, a constant compressive strain of $25 \%$ is applied to carbon black-filled butyl rubber, and we monitor the stress relaxation. The test temperature is initially $22{ }^{\circ} \mathrm{C}$, but after a week, the temperature is increased to $80{ }^{\circ} \mathrm{C}$. A significant drop in stress is seen very quickly. To fairly compare the 22 and $80^{\circ} \mathrm{C}$ data, we need to apply a temperature shift. However, we mentioned earlier that this shift is ambiguous. If we shift horizontally by the unfilled butyl parameters, we might conclude that the equilibrium modulus is temperature dependent [vertical shifts are required]. If we use the "best" fit factors [which are quite anomalous], we conclude that no such dependence need be invoked. In the absence of conclusive proof one way or the other, we may want to employ horizontal shifts only [i.e. use the "best" fit factors] 


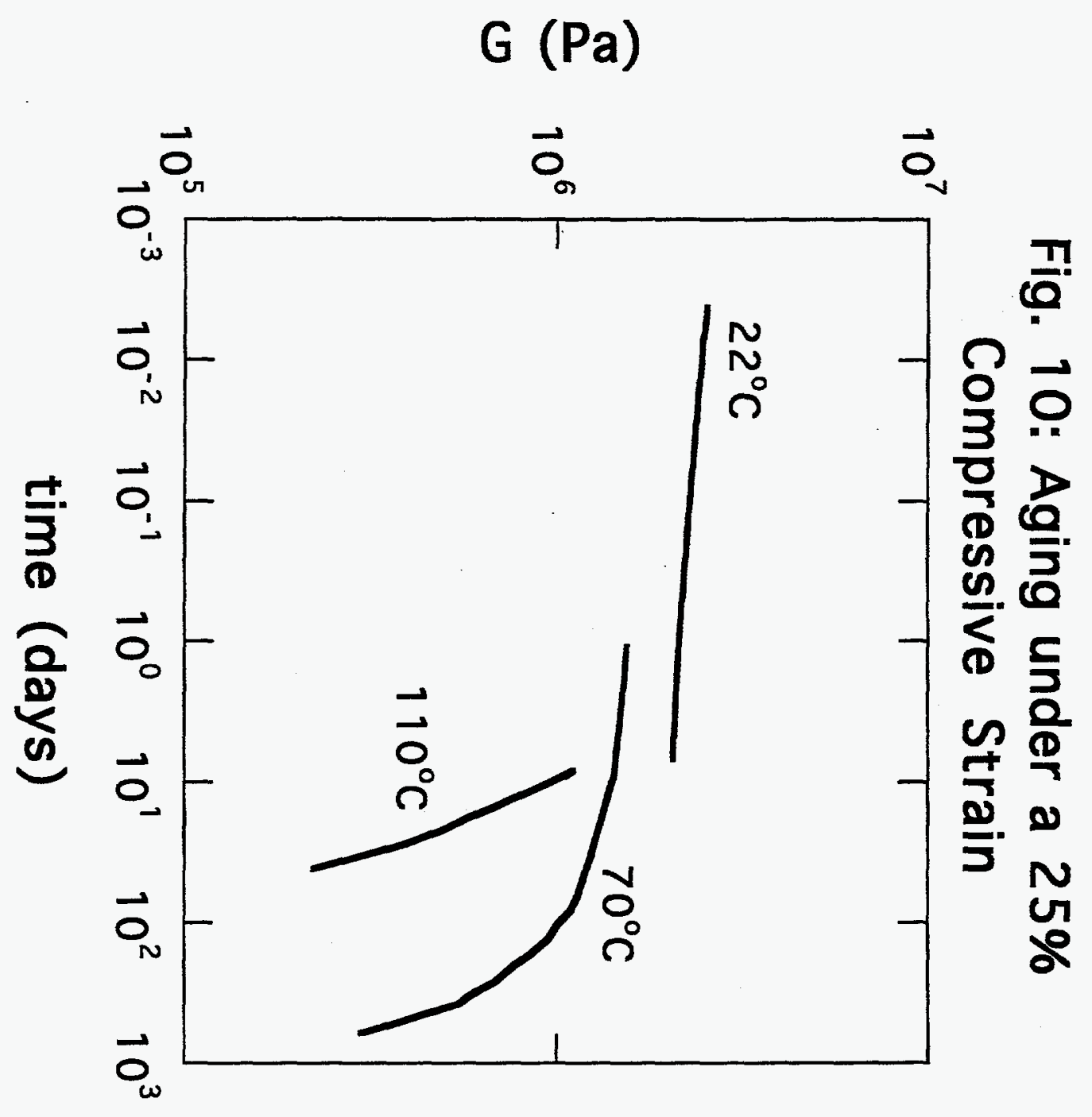


Fig. 11: Horizontal vs. Vertical Temperature Shifts

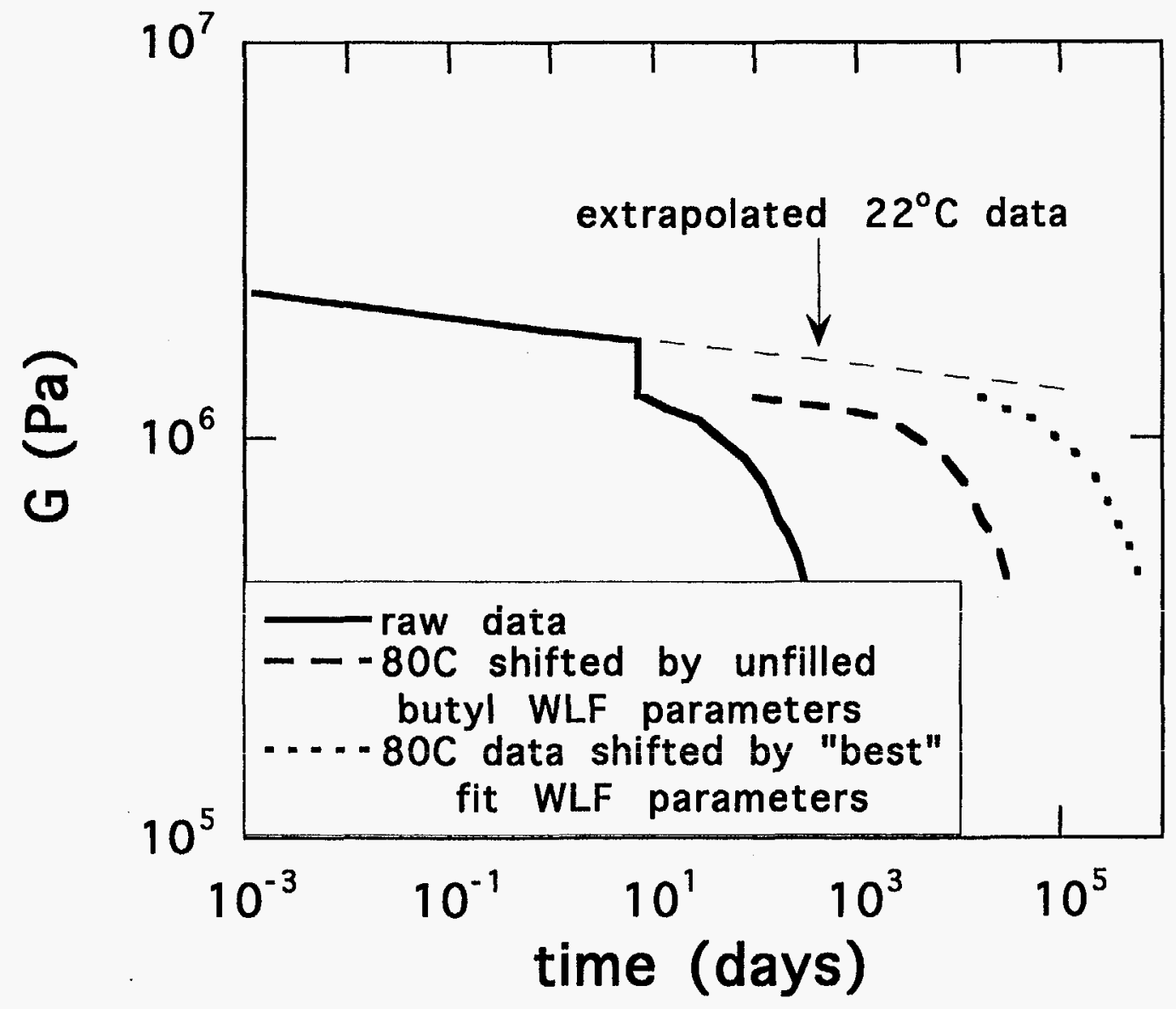


since this path is consistent with Eqs. 4 and 5. Including vertical shifts would be more difficult, yet no more rigorous.

\section{Applications}

\section{A. Predicting O-Ring Lifetime}

From the discussions above, we can assume linear elastic behavior in our analysis of butyl o-ring lifetimes. O-rings are typically compressed to a constant $25 \%$ in service. At these high strains, we showed that the decaying portion of the stress relaxation modulus has softened so greatly that the measured stress reflects the equilibrium modulus. And we are not concerned with the short time response, since o-ring lifetimes are measured in decades.

Of more concern might be the analysis of accelerated aging tests since the time scales are now measured in months. Here, too, the applied strains are $25 \%$ and the high temperatures accelerate relaxation times as well. From Fig. 6, we see that, to a high degree, the stresses measured reflect the equilibrium modulus and a linear elastic analysis is adequate. More importantly, from Fig. 11, we see that the remaining viscoelastic relaxations might reduce the stress by a factor of two [remember from Fig. 7 , we estimated that $\mathrm{G}_{\infty}=1 \times 10^{6} \mathrm{~Pa}$ ]. However, when degradation occurs, the stress decays by an order of magnitude. Therefore, viscoelasticity is relatively unimportant when compared to chemistry for these analyses.

A potential problem results from our inability to separate unambiguously the horizontal and vertical temperature shifts. We stated above that, for the sake of simplicity, we assume the effects reside completely in the horizontal [i.e. time] shifts. However, if a horizontal shift is required, the measured elastic stress will depend upon temperature as seen in Fig. 11.

Not only does an elastic response simplify stress calculation, but it also simplifies the interpretation of the accelerated aging tests. Since the 
equilibrium modulus is propotional to the crosslink density, stress decay implies chain scission and the resulting activation energies reflect chemistry unclouded by viscoelastic effects. However, diffusion limitations are still a problem. ${ }^{1}$

\section{B. Evaluating Field-Return O-Rings}

The analyses are much more complicated for tests evaluating o-rings returning from the stockpile. Our standard metric for o-ring health is compression set. In this test, the o-ring is removed from service, and after some time and temperature history, its height, L, is measured and compared to the original height, $\mathrm{L}_{0}$. Compression set is defined as

$$
\text { C.S. }=\frac{\mathrm{L}_{\mathrm{o}}-\mathrm{L}}{\mathrm{L}_{\mathrm{o}}-\mathrm{L}_{\mathrm{c}}}
$$

where $L_{C}$ is the compressed, in-service height. If no crosslink chemistry occurs, C.S. equals 0 . If all original crosslinks are broken and reformed in the compressed state, C.S. equals 1.

Immediately, we see that a simple elastic analysis is inappropriate since the unloading step strain results in a viscoelastic response. Moreover, the unloading releases the strain and we can no longer take advantage of strain softening of the decaying term, $G_{d}$, to minimize its impact. In fact, the nonlinear viscoelastic term becomes more important as compression set achieves its ultimate value. Since viscoelasticity is important, it implies that the time-temperature history during unloading and subsequent annealing must be monitored carefully [typically not true].

A simple elastic representation can no longer even be applied to the long-time stress, $\sigma_{\infty}$. It no longer equals $G_{\infty} \gamma$, since crosslinks are being broken and formed in differing states of strain. This state of strain at the point of formation or breakage is critical to the resultant stress. A 
relatively easy way to account for these effects in $\sigma_{\infty}$ was developed by Dan Segalman. 6

$$
\frac{\mathrm{d} \sigma_{\infty}}{\mathrm{dt}}+\mathrm{k}(\mathrm{T}) \sigma_{\infty}=\mathrm{G}_{\infty}^{\mathrm{o}} \dot{\gamma}
$$

We showed earlier that the initial equilibrium modulus, $\mathrm{G}_{\infty} \mathrm{O}$, equalled $1 \times 10^{6} \mathrm{~Pa}$. For butyl rubber, Fig. 9 demonstrated that the rates of crosslink scission and formation were roughly equal. Gillen ${ }^{1}$ has shown that these rates, $k(T)$, have the typical Arrhenius form.

$$
k(T)=k_{o} e^{-E / R T}
$$

Problems also arise from a more practical consideration in that we do not know the original o-ring height, $\mathrm{L}_{\mathrm{O}}$. For example, consider an oring of nominal height $1 \mathrm{~mm}$ with a minor variation of $10 \%$ [actual variations can be much worse] compressed to $0.75 \mathrm{~mm}$. An o-ring of $0.9 \mathrm{~mm}$ original height with a "good" compression set of 0.3 and one of $1.1 \mathrm{~mm}$ original height with a "bad" set of 0.7 will appear to have identical sets of 0.58 if we assume the actual original heights were $1.0 \mathrm{~mm}$.

Finally, we remember from Fig. 9 that the only significant "aging" of butyl rubber occurred in the first day and was attributed to incomplete cure of the sheet stock. If this result holds for o-rings as well as for sheet stock, significant crosslink formation would occur that would manifest itself as a fictitiously high compression set.

We conclude that compression set is not a very useful tool for assessing the state of stockpile o-rings. However, such a test is necessary and we wonder if some better test could be devised. We wish this test could be free from viscoelastic effects and insensitive to actual original height. The former requires high strains, so we first propose that the butyl be compressed to higher strains than seen in service [ $>30 \%]$ such that even if significant set occurs, substantial strain softening is still active and the 
equilibrium modulus [i.e. elastic response] is dominant. Secondly, we propose that the actual force at a prescribed compression be measured rather than an indirect measure such as compression set. The advantage of this procedure is in its insensitivity to original height. The disadvantage lies in that the variation in original heights obscures interpretation of chemical degradation alone. However, the resulting measurements will directly reflect the distribution and change in sealing force of stockpile orings.

In Fig. 12, we show the results of this test for virgin butyl rubber and that aged at $120^{\circ} \mathrm{C}$ for 10 days under $25 \%$ compressive strain [original height $=1.15 \mathrm{~mm}$ for both]. The force of each sample was measured at compressive strains of 30,40 and $50 \%$ for 1 day, at which time, the force was no longer decaying, indicative of elastic response. A significant loss of sealing force is observed in the aged sample at all strains. Unfortunately, the virgin response is quite nonlinear, so estimation of the sealing force at $25 \%$ compressive strain is not straightforward. Perhaps the best path simply accepts the $30 \%$ strain values as the metric of aging. Practically, then, we would monitor the sealing force at $30 \%$ strain of field-return orings as a function of service lifetime. For the tests in Fig. 12, we see a $55 \%$ decrease in sealing force at $0.8 \mathrm{~mm}$ [30\% strain] in the aged sample. While we do not yet have a fundamental understanding of the mechanism of oring failure, it is clear that any proposed failure mechanism will directly correlate with sealing force, and a relative decrease of $1 / 2$ in this force is probably nearing the point of concern. Future effort should be expended to determine more accurately the actual critical sealing force. 
compressive force (Ibs)

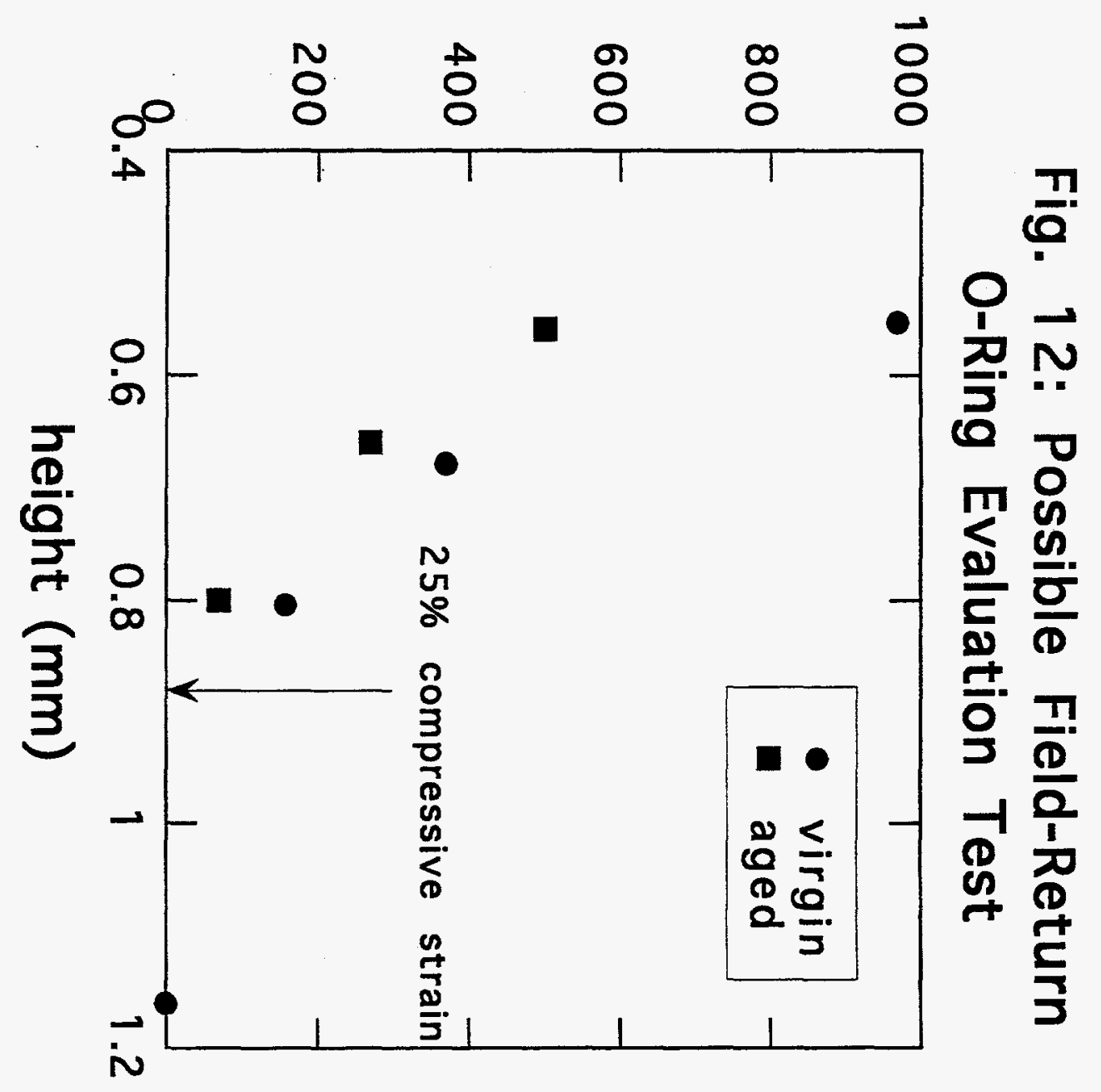




\section{References}

(1) K. Gillen and R. Clough, Handbook of Polymer Science and Technology, N. P. Cheremisinoff, Ed.: Marcel Dekker, NY, 1991.

(2) D. Adolf, Sandia Report, SAND95-1501, 1995.

(3) D. Adolf, Sandia Report, SAND96-1313, 1996.

(4) J. D. Ferry, Viscoelastic Properties of Polymers, Wiley, NY, 1980.

(5) R. G. Larson, Constitutive Equations for Polymer Melts and Solutions, Butterworths, Boston, 1988.

(6) D. Segalman, internal SNL memo, 5/30/97. 


\begin{tabular}{|c|c|c|}
\hline 1 & MS9018 & Central Technical Files, 8940-2 \\
\hline 5 & 0899 & Technical Library, 4916 \\
\hline 2 & 0619 & $\begin{array}{l}\text { Review \& Approval Desk, } 12690 \\
\text { For DOE/OSTI }\end{array}$ \\
\hline 10 & 0333 & Doug Adolf, 1841 \\
\hline 1 & 0961 & John Sayre, 1403 \\
\hline 1 & 0958 & Carol Adkins, 1472 \\
\hline 1 & 0958 & Ginger De Marquis, 1472 \\
\hline 1 & 0958 & Mark Stavig, 1472 \\
\hline 1 & 0342 & Dick Salzbrenner, 1805 \\
\hline 1 & 1407 & Roger Clough, 1811 \\
\hline 1 & 1407 & Ken Gillen, 1811 \\
\hline 1 & 0333 & Al Hurd, 1841 \\
\hline 1 & 0339 & John Curro, 1870 \\
\hline 1 & 0328 & Marty Stevenson, 2674 \\
\hline 1 & 9404 & Linda Domeier, 8713 \\
\hline 1 & 9042 & Larry Weingarten, 8742 \\
\hline 1 & 0443 & Bob Chambers, 9117 \\
\hline 1 & 0443 & Steve Burchett, 9117 \\
\hline 1 & 0443 & Hal Morgan, 9117 \\
\hline
\end{tabular}


